\title{
Inovação no acervo e no acesso de informações: o sistema de repositório institucional nos Tribunais de Contas do Brasil
}

Sílvia Maria Berté Volpato

Bibliotecária, estudante de Pós-Doutorado em Administração na UNINOVE

Leonel Cezar Rodrigues,

Programa de Pós-Graduação em Administração PPGA.Universidade Nove de Julho - UNINOVE

Amélia Silveira

Programa de Pós-Graduação em Administração PPGAUniversidade Nove de Julho - UNINOVE

http://dx.doi.org/10.1590/1981-5344/1917

Esta pesquisa apresenta os resultados de um estudo que investigou a viabilidade de implantação de repositório institucional nos Tribunais de Contas do Brasil. Os repositórios se apresentam como uma tendência em organizações voltadas para a inovação, a exemplo de universidades, havendo ferramentas gratuitas para sua adoção. Para tanto, os procedimentos metodológicos utilizados envolveram, inicialmente, uma pesquisa descritiva, com método quantitativo e de levantamento; exploratória, com método qualitativo, e adoção da técnica Delphi, no momento seguinte. Como resultado apresenta a efetivação da inovação sujeita à adoção das diretrizes de caráter institucional, estrutural e operacional, para implantação de inovação arquitetural nas bibliotecas dos Tribunais de Contas e descreve os elementos estruturantes de cada um deles e enfatiza a magnitude e os benefícios que poderão ocorrer nas instituições com a implantação do repositório institucional.

Palavras-chave: Inovação. Repositório institucional. Bibliotecas especializadas. Tribunais de Contas. 


\title{
Innovation in the collection and in the information access: the institutional repository system in the Courts of Accounts in Brazil
}

\begin{abstract}
This research presents the results of a study that investigated the feasibility of implementing an institutional repository in the Courts of Accounts in Brazil. The repositories are presented as a tendency in organizations devoted to innovation, such as universities, with free tools for adoption. Therefore, the applied methodological procedures involved initially a descriptive research with data collection and quantitative method, and in the next moment; a exploratory research with qualitative method and the adoption of the Delphi technique. As a result, this research presents the effectiveness of the innovation subject to the adoption of guidelines with institutional, structural and operational character, for implementing architectural innovation in the libraries of the Courts of Accounts, and also describes the structural elements of each guideline and emphasizes the magnitude and the benefits that may occur in the institutions with the institutional repository implementation.
\end{abstract}

Keywords: Innovation. Institutional repository. Specialized libraries. Courts of Accounts.

Recebido em 14.11.2013 Aceito em 18.09.2014

\section{Introdução}

A inovação passou a ser, de modo figurativo, a partir das duas últimas décadas, o fator que delimita o desenvolvimento e o sucesso em empresas e países. Seu conceito envolve qualidade e uma gama maior de produtos, mas é preciso que sejam ofertadas novidades, aperfeiçoamentos e características totalmente novas em relação aos produtos já existentes. Adotar inovações representa gerar, desenvolver e implantar ideias ou procedimentos novos. Assim, esses podem ser novos produtos ou serviços, novas tecnologias para procedimentos produtivos, novas estruturas ou sistemas administrativos, ou mesmo elementos novos na acepção de inovar. A inovação é uma opção para fomentar modificações na organização, seja com o objetivo de responder às 
mudanças nos ambientes interno ou externo, ou ao menos, antecipar-se às exigências do mundo da tecnologia.

O avanço tecnológico tem alterado os métodos e processos de trabalho nas organizações, advindo daí a necessidade de identificar novas ferramentas de gestão e organização da informação. Com essa finalidade, as organizações têm implementado instrumentos de gestão de conteúdos que possibilitam conduzir de maneira eficaz e eficiente as ações da organização. Neste contexto se inserem as Bibliotecas. Essas sofreram mudanças contextuais, estruturais, normativas e administrativas, agregando novas perspectivas as suas missões. Atentando-se para a importância dos repositórios institucionais para as bibliotecas na era contemporânea, a presente pesquisa enquadra-se nos muitos esforços que estão se realizando por parte de estudiosos da área de Biblioteconomia e Ciência da Informação para estruturar sistemas que possam suprir as necessidades de informações oriundas de questões múltiplas. Se de um lado tem-se o interagente, cuja satisfação é o fim último da biblioteca; de outro, tem-se o bibliotecário como gestor da informação, cujo papel é empenhar-se em descobrir o desejo do usuário e, consequentemente, aparelhar a biblioteca de maneira a beneficiá-la de instrumentos eficazes na recuperação de informações. O acervo poderá influenciar positivamente nas relações sociais, à medida que reafirmar seu caráter educacional eminente. Como consequência desse processo pode se destacar, segundo Procópio (2005): a) o desenvolvimento pessoal; b) a possibilidade de aprimoramento profissional $e ; c) \quad o$ acesso aos conhecimentos trazidos pela mídia eletrônica, entre outros. Além disso, em decorrência das tecnologias atualmente disponíveis possibilitarem que o processo gerencial seja mais ágil, o tema proposto deverá contribuir sobremaneira para uma postura proativa dos gestores das bibliotecas aqui analisadas, bem como para os de outras bibliotecas que apresentem semelhança ou que estejam em consonância com o que se discutiu neste trabalho.

O objetivo geral deste estudo foi propor diretrizes para a implantação de Repositório Institucional (RI), como inovação estrutural, nos Tribunais de Contas do Brasil.

Este artigo está estruturado da seguinte maneira: na primeira parte, da qual esta introdução é elemento agregado, apresenta-se o contexto e o objetivo de pesquisa. Em seguida, apresenta-se a revisão de literatura sobre inovação, tecnologias da informação e da comunicação (TIC), repositórios institucionais e de acesso aberto. Na terceira parte, destacam-se os procedimentos metodológicos utilizados para o alcance do objetivo proposto. Na quarta parte os dados coletados no estudo de campo são apresentados e analisados, sendo que na quinta e última parte, encontram-se as considerações finais, seguida da lista de referências citadas. 


\section{Revisão de literatura}

Inovação é tema constante nos debates sobre competitividade e sobrevivência das organizações. É reputada pelos estudiosos das organizações como o processo marcado pela descontinuidade: o que já está estabelecido e concebido por meio da introdução de um novo bem ou de um bem de qualidade superior, de um novo método de produção, de um novo mercado, de uma nova fonte de matéria-prima ou, até mesmo, de uma nova forma de organização (SCHUMPETER, 1961).

Na história das organizações existem vários exemplos de empresas bem sucedidas e de outras mal sucedidas. A inovação é um dos fatores. Empresas que inovaram e visualizaram novos processos de gerenciamento de serviços e produtos são as que resistiram ao tempo, romperam com as estruturas tradicionais e partiram para a mudança.

Segundo Henderson; Clark (1990), as inovações podem ser de diferentes tipos, com diferentes efeitos competitivos. Os autores consideram que as inovações podem ser classificadas ao longo de duas dimensões: impacto das inovações nos componentes e; impacto nas ligações entre os componentes. De acordo com o modelo, referente a estratégias de empresas inovadoras para entrada no mercado (projeto dominante), existem quatro tipos de inovação: incremental, consolida as capacidades tecnológicas das empresas, por exemplo, tecnologia de componentes e a arquitetura do produto; radical, exige o uso de novas capacidades técnicas e comerciais e o emprego de novos enfoques para a solução de problemas, exemplo: utilização de fibra ótica em vez de metal nas comunicações; arquitetural, modifica a maneira na qual os componentes de um produto são interligados, enquanto deixa intactos os conceitos fundamentais do projeto e; modular, modifica somente os conceitos fundamentais do projeto de uma tecnologia, exemplo: introdução de nova tecnologia de componentes inserida dentro de uma arquitetura sem modificações.

Cabe esclarecer que a inovação pode ser entendida como uma alternativa para promover modificações na organização, seja com o objetivo de responder às mudanças nos ambientes internos ou externos, seja como forma de uma ação antecipada ante os concorrentes, seja com o intuito de influenciar o ambiente organizacional (DAMANPOUR, 1991), sendo ainda suporte e guarida para a tecnologia e a modernização. Os aspectos que sustentam uma organização inovadora, segundo Knox (2002), são a cultura e o clima organizacional; as capacidades e as habilidades de gerenciamento; o controle e a estrutura organizacional; por fim, novos produtos e desenvolvimento de processos.

No ambiente da organização, a Tecnologia de Informação e Comunicação (TIC) tornou-se um recurso essencial para auxiliá-la em seu posicionamento estratégico, visto que influencia na tomada de decisão, na estrutura organizacional, na cultura e, por fim, nos paradigmas organizacionais em geral. As TIC transformaram espaços e tempos. As fronteiras internas também se modificam, e, com isso, surgem novos 
espaços para a aprendizagem, muito mais ligados ao mundo do trabalho. A intensificação crescente das TIC destaca uma diversidade de fontes de informação que modificam, ampliam e agilizam a capacidade de comunicação da informação em todos os níveis e setores da sociedade. Na esfera da ciência, das universidades e das instituições de pesquisa, tal condição cria possibilidades que favorecem extraordinariamente a divulgação de resultados. Surgem também novos cenários de ação compartilhada, projetos para a formulação de novas práticas complementares, novas expectativas, novas demandas, novas ofertas inovadoras, o que requer atualização e educação contínuas.

A Internet também modificou a forma como os pesquisadores produzem e comunicam os resultados de suas investigações, sobretudo pela agilidade e visibilidade que proporciona. Segundo o Instituto Brasileiro de Informação em Ciência e Tecnologia (IBICT), o Brasil caminha a passos largos para estabelecer uma sociedade de conhecimento, que tenha acesso totalmente livre e gratuito à informação científica (IBICT, 2012). A esse advento do mundo digital são relacionadas novas mudanças no trabalho dos profissionais da informação, o que exige não somente o aperfeiçoamento de técnicas antigas, mas também seu ajustamento às novas tecnologias. Gerir o conhecimento demanda que esses profissionais tenham aptidões nas técnicas bibliotecárias, preocupação voltada para a mudança, como criatividade e familiaridade com a tecnologia, conhecimento dos temas em que atua a instituição da qual a biblioteca faz parte. Para isso, é importante que o gestor bibliotecário institua formas de geração, uso, organização e disseminação dos diversos produtos informacionais, que, nos dias atuais, não se admitem sem os meios eletrônicos e virtuais. $E$, sem acesso às redes de informação, pelo acesso à informação em tempo real, o qual se impõe graças às TIC, na busca da democratização do saber.

Pelo mundo há ações como o Movimento de Acesso Aberto (Open Access Movement), surgido nos Estados Unidos em 1990, e o projeto Creative Commons (CC), que têm contribuído para o surgimento de outras possibilidades do uso da informação e para a adoção do acesso aberto. Quer seja disponibilizando integralmente conteúdos acadêmicos e científicos que se utilizam de TIC em ambientes como os repositórios, cuja finalidade é oferecer um conjunto de serviços à comunidade da instituição a qual as próprias TIC estejam vinculadas; quer seja gerenciando e disseminando conteúdos digitais, criados pela instituição e pelos membros da sua comunidade. É fundamentalmente um compromisso organizacional com a gestão dos conteúdos digitais, sua preservação em longo prazo, organização e acesso.

No Brasil, o IBICT lidera o processo de disseminação da produção técnico-científica pelas instituições de ensino superior e pesquisa, comprovando a liderança e capacidade desse Instituto em elaborar e coordenar programas e ações de incentivo para que as instituições de ensino e pesquisa de todo o país disponibilizem, por meio do acesso aberto, sua produção científica (SILVA; ALCARÁ, 2009). Leite (2009) 
salienta que os repositórios de acesso aberto possibilitam o acesso sem barreiras à informação científica, à comunidade científica. Sendo que, o seu adequado planejamento, implementação e adoção promove o aumento da visibilidade dos resultados de pesquisa, do pesquisador e da própria instituição.

\subsection{Repositórios institucionais}

O desenvolvimento de repositórios institucionais surgiu em 2002, como uma nova estratégia que permitiu às universidades assumirem 0 papel de editoras, modernizando os processos de publicação e divulgando a produção acadêmica em conteúdo digital (LYNCH, 2003). Repositório institucional para esse autor é

um conjunto de serviços que a universidade oferece para os membros de sua comunidade para o gerenciamento e a disseminação de conteúdos digitais, criados pela instituição e membros da sua comunidade. É essencialmente um compromisso organizacional com a gestão, desses conteúdos digitais, inclusive preservação de longo prazo, quando apropriado, bem como organização e acesso ou distribuição (LYNCH, 2003, p. 2).

Os repositórios institucionais inserem-se num movimento mais amplo de acesso livre ao conhecimento. São geralmente consideradas duas vias paralelas para o acesso livre ao conhecimento: revistas com acesso livre, nas quais os artigos ficam disponíveis sem restrições desde a sua publicação e o autoarquivamento pelos autores dos seus trabalhos em repositórios institucionais, a partir dos quais podem ser acessadas livremente.

O repositório institucional serve como um ambiente para reunir acervos, serviços e pessoas para estabelecer um ciclo de vida completo de criação, disseminação, uso e preservação de dados, informações e conhecimentos. Assim, a construção de um repositório institucional requer fontes de conteúdo em forma digital, seja digitalizados ou nascidos com conteúdo digital. Por outro lado os repositórios institucionais são coleções que capturam e preservam a produção intelectual de uma ou mais universidades ou comunidades (CROW, 2002) ou ainda um conjunto de serviços que uma universidade oferece aos membros de sua comunidade a fim de gerenciar e disseminar materiais digitais criados pela instituição e membros da comunidade ( $L Y N C H, 2003)$. Portanto, o que caracteriza os repositórios institucionais é o fato de serem orientados para a informação produzida no ambiente das instituições, sendo desenvolvidos, implementados e mantidos por elas (TOMAÉL; SILVA, 2007). Por sua vez Kuramoto (2005, p. 84), entende que os repositórios institucionais "[...] são um conjunto de serviços oferecidos por uma instituição para os membros de sua comunidade, para a gestão e disseminação da sua 
produção técnico-científica em meio digital", ao passo que os repositórios temáticos "[...] são um conjunto de serviços oferecidos por uma sociedade, associação ou organização, para gestão e disseminação da produção técnico-científica em meio digital" (KURAMOTO, 2006, p. 83).

Para Leite (2012), um repositório institucional é um serviço de informação científica digital em ambiente interoperável e aberto, dedicado ao gerenciamento da informação científica de uma instituição de ensino e/ou pesquisa com vistas à maximização de seu acesso, uso e impacto. Nesse sentido, a informação e o conhecimento são elementos-chave para a transformação social, econômica, técnica e científica de uma sociedade. Assim, para Ribeiro Júnior (2012, p. 154) "a disseminação do conhecimento científico e tecnológico é um dos quesitos para promover mudanças de longo prazo que tornem permanentes as características desejáveis de uma sociedade do conhecimento". Sayão; Marcondes (2009) afirmam que, por todo o mundo, as universidades e os centros de pesquisa estão, de uma forma muito intensa, planejando, implementando ou operando repositórios institucionais. Esse movimento coletivo é parte do esforço das comunidades acadêmicas de explorar as possibilidades oferecidas pelas tecnologias de informação e comunicação para criar serviços de informação inovadores, através dos quais as novas mídias digitais possam potencializar o ensino, a pesquisa e a comunicação científica.

Como opção para o acesso e uso da literatura científica, as bibliotecas, os centros de informações, universidades e editoras, utilizam novos canais de comunicação com vistas a prestar aos pesquisadores agilidade na troca de informação entre os pares (RIBEIRO JÚNIOR, 2012). Na visão do autor, a criação de canais de disseminação da produção científica e tecnológica na forma de repositórios institucionais é cada vez mais percebida como um condutor central dos produtos das atividades de Ciência, Tecnologia e Inovação (CT\&I), nos quais são criados espaços para os autores constituírem um meio de divulgar rapidamente a produção realizada em nível institucional para a comunidade acadêmica interna e externa de uma universidade. Sintetizadamente, um repositório institucional compreende-se em: organizar, preservar, recuperar e disseminar a Informação Científica produzida no âmbito institucional. Dessa maneira, Lynch (2003, p. 2) assevera que um repositório institucional:

consiste em um conjunto de serviços que a universidade oferece para os membros da sua comunidade com vistas ao gerenciamento e disseminação do material digital criado pela instituição e pelos seus membros.

Sendo que, o uso efetivo das operações de um repositório institucional pode gerar inúmeros benefícios ao público a que é destinado, ou seja, a comunidade acadêmica em geral. 
Os atributos de um repositório institucional, segundo Crow (2002) são os: institucionalmente definidos; científicos ou academicamente orientados; cumulativos e perpétuos; livres e interoperáveis (aberto); não efêmeros (conteúdos digitais) e; com foco na comunidade. Leite (2012) destaca que os repositórios institucionais: não concorrem com periódicos, apenas complementam/potencializam algumas de suas funções; serem avaliados por pares é uma função dos periódicos e não do repositório institucional e; os repositórios institucionais não publicam, apenas tornam os conteúdos públicos e acessíveis. Um repositório institucional colaborativo permite que bibliotecas públicas e especializadas formem redes de informações digitais, em resposta às demandas da sociedade da informação.

Outros benefícios decorrentes são reforçados de forma precisa por Prosser (2005), que atenta que estes ocorrem em três perspectivas:

Para o indivíduo - propicia um repositório central para o trabalho do pesquisador; por ser livre e aberto, aumenta a divulgação e o impacto da pesquisa do indivíduo, além disso, exerce a função de um currículo para o pesquisador;

Para a instituição - estende a visibilidade e o prestígio da instituição, ao reunir toda a escala e extensão da pesquisa que é da sua área de interesse e intervenção. Atua como um meio de divulgação da mesma, com vistas às fontes de financiamento, bem como agrupa novos pesquisadores e estudantes;

Para a sociedade - fornece acesso à pesquisa desenvolvida em todo o mundo; garante a preservação, em longo prazo, da produção das instituições acadêmicas; disponibiliza grande volume de documentos sem impacto relevante nos custos de arquivamento.

Por sua vez a constituição de um repositório institucional torna necessário estabelecer políticas para sua implementação, sua gestão e efetivo funcionamento. As políticas do repositório devem estar disponíveis para os usuários, em local de fácil visualização, no próprio repositório. Leite (2009) salienta que as políticas asseguram o funcionamento dos repositórios de forma eficiente e eficaz. Tomaél e Silva (2007, p. 4-5) defendem que a política, baseada na cultura da instituição, deve prever aspectos relativos a:

1) responsabilidade pela criação, implementação e manutenção do repositório; 2) conteúdo proposto e implementado; 3) aspectos legais relativos a documentos e licenças de softwares; 4) padrões; 5) diretrizes para preservação digital; 6) política e níveis de acesso e; 7) sustentabilidade e financiamento do repositório. 
Deve ficar claro, entretanto, que para o êxito do repositório institucional, não é suficiente, somente, a instalação de programa apropriado. São indispensáveis, finalidades bem definidas e planejamento elaborado. Focar só na tecnologia conduz a iniciativa ao insucesso (COSTA; LEITE,2010).

Pode-se perceber dessa forma, o surgimento de um novo tempo para a biblioteca, na qual os gestores que lidam com a informação como atividade fim, encontram-se, mais do que nunca, desafiados, uma vez que as inovações tecnológicas vêm encurtando o tempo e o acesso às informações (LANCASTER, 1993). As bibliotecas estão, assim, estimuladas e pressionadas pelo desafio de inovar, e mudar sua forma de trabalho. Dentre outras perspectivas, os repositórios digitais se constituem em alternativa viável de inovação, em bibliotecas.

\section{Procedimentos metodológicos}

Esta pesquisa teve por objetivo propor diretrizes para a implantação de Repositório Institucional, como inovação estrutural, nos Tribunais de Contas do Brasil. Foi definida em duas etapas: descritiva, com método quantitativo e de levantamento, no primeiro momento, e exploratória, com método qualitativo, e adoção da técnica de Delphi, no momento seguinte. Dos 34 Tribunais de Contas do Brasil, dentre os da União, Distrito Federal, Estados e Municípios, 29 contam com bibliotecas estruturadas.

No primeiro momento, um questionário estruturado, com questões fechadas e abertas foi adotado. O questionário seguiu um processo metodológico de aplicação efetuado em três fases: construção, distribuição e análise. Com relação à fase de construção, o questionário foi elaborado com base na revisão de literatura, nos objetivos e questões de investigação desse estudo. No que se refere à fase de distribuição, os questionários foram entregues aos 29 gestores dessas bibliotecas, os quais se constituíram em sujeitos sociais da pesquisa, sendo essa amostra intencional, e de cunho censitário. Primeiramente, os gestores foram questionados quanto à estrutura, serviços e produtos da biblioteca. Depois, sobre o entendimento quanto à criação de um repositório institucional, suas possibilidades de uso e de aplicação nessas bibliotecas dos Tribunais de Contas do Brasil. Refira-se que, de um total de 29 questionários enviados aos gestores das bibliotecas, todos $(100 \%$ de retorno) foram devolvidos. Aplicados os questionários, procedeu-se ao levantamento dos dados, e por último, à análise dos mesmos.

De posse dos resultados evidenciados nesta pesquisa de campo com esses gestores, e entendendo que o assunto sobre repositórios institucionais deveria ser ainda aprofundado neste estudo, prosseguiu-se com a segunda etapa de pesquisa, a fase exploratória, por meio do estudo Delphi. 
O estudo Delphi constituiu-se de duas partes, a primeira contemplou a elaboração de uma listagem de afirmativas que servisse de subsídio para a criação do repositório institucional nos Tribunais de Contas e de perguntas abertas, pelo qual se buscou o consenso de opiniões entre os participantes do painel Delphi. A segunda parte buscou a confirmação pelos especialistas das respostas, do apanhado das respostas da primeira parte. Para tanto, foram considerados sujeitos sociais, cinco especialistas (oráculos) em repositórios institucionais no Brasil. Ou seja, especialistas brasileiros da área de Ciência da Informação com conhecimento e experiência, autores no tema de repositórios institucionais. Essa amostra foi definida como intencional, de conveniência e por acessibilidade.

A técnica, cuja utilização como ferramenta para formular julgamentos colaborativos e para apoiar a criação do repositório institucional, enriqueceu a pesquisa, pelo aporte de informações e conhecimentos que proporcionou.

A técnica Delphi teve seu nome baseado no antigo Oráculo grego de Delfos, lugar sagrado na Grécia antiga, onde eram oferecidas visões do futuro para aqueles que procuravam seus conselhos. É uma técnica de previsão, projetada para conhecer com antecipação a probabilidade de eventos futuros. Prevê a solicitação e coleta sistemática da opinião de especialistas em um determinado assunto.

A literatura consultada apresenta a técnica como uma forma de pesquisa qualitativa, que busca o consenso da opinião de um grupo de especialistas a respeito de um determinado evento futuro, por meio de rodadas interativas de questionamentos, que busca deduzir, refinar e gerar uma opinião final a partir de um grupo de especialistas (HELMER, 1966; SÁFADI, 2001).

Nessa fase da pesquisa, um roteiro serviu como base para a coleta de dados quanto à definição do conjunto de diretrizes a serem propostas para a implantação do repositório institucional nos Tribunais de Contas do Brasil. Esse roteiro foi organizado de forma a permitir que cada especialista pudesse emitir comentários sobre as diretrizes consideradas relevantes para a implantação do repositório institucional, como inovação, de acordo com suas experiências e conhecimentos.

Após a descrição dos procedimentos metodológicos, passar-se-á à apresentação e análise dos resultados.

\section{Apresentação e análise dos resultados}

Visando contextualizar as instituições onde será proposta a implantação do repositório e evidenciar sua importância, insere-se um breve relato dos Tribunais de Contas do Brasil e o diagnóstico de suas bibliotecas. Em seguida, dá-se início à consulta aos especialistas em repositórios institucionais no Brasil, com ênfase ao repositório institucional a ser implantado nos Tribunais de Contas. Com isso, iniciou-se a utilização da técnica Delphi, com o intuito de buscar um consenso das opiniões dos especialistas quando se analisa os resultados de pesquisa. 
Os Tribunais de Contas são órgãos responsáveis pelo controle externo das atividades das entidades tanto da administração direta como da indireta. Administrar a atividade do gerenciamento do dinheiro público, desde a possibilidade de arrecadação até a sua efetiva distribuição, de acordo com metas sociais, é no qual atua o controle, evitando o desvio nas destinações prefixadas nas leis de planejamento. Presentemente, as competências $e$ as regras para o delineamento da estrutura e funcionamento dos Tribunais de Contas do Brasil, no que couber, estão definidas na Constituição da República (BRASIL, 1988) e nas respectivas Constituições Estaduais.

No cumprimento de suas missões constitucionais, as cortes de contas exercem quatro funções precípuas: função opinativa, quando os tribunais apreciam as contas do chefe do poder executivo, emitindo parecer prévio, laboram em prol do legislativo, posto este ser o titular do julgamento político das contas anuais; função jurisdicional, quando os tribunais de contas, pelas competências expressas no inciso II do Art. 71 da $C F$, julgam e liquidam as contas dos administradores públicos e demais responsáveis por dinheiros, bens e valores públicos, além das contas daqueles que derem causa a perda, extravio ou outra irregularidade de que resulte prejuízo ao erário; função corretiva, o item VIII do Art. 71 da CF prevê a possibilidade de o Tribunal de Contas aplicar, quando for constatada ilegalidade de despesa ou irregularidade das contas, as sanções previstas em lei, podendo fixar multa proporcional ao dano causado, além de outras cominações, visando a recomposição do erário e; a função fiscalizadora, prevista nos incisos IV, V e VI do Art. citado, que dispõe acerca da possibilidade de ampla atuação das cortes de contas, ou seja na área contábil, financeira, orçamentária operacional ou patrimonial, quando serão verificados os aspectos da legalidade, legitimidade e economicidade dos atos administrativos (GUERRA, 2003).

Os Tribunais de Contas atuam também na função de assessoramento, quando representam ou recomendam à autoridade competente para corrigir eventuais erros $e$; na função orientadora, quando realizam cursos, debates e reuniões (sede ou interior) orientam os administradores públicos.

No Brasil, há um Tribunal de Contas da União (TCU), 27 Tribunais de Contas dos Estados, incluindo o Tribunal de Contas do Distrito Federal, e quatro Tribunais de Contas dos Municípios, mais os Tribunais de Contas específicos para as capitais dos Estados do Rio de Janeiro e de São Paulo.

As cortes são compostas por ministros ou conselheiros, procuradores e técnicos: aos primeiros compete discutir e julgar os assuntos sujeitos ao controle externo; aos segundos cabe defender a ordem jurídica; e aos técnicos compete instruir os processos de tomadas e prestações de contas, bem como elaborar os relatórios de auditoria para posterior julgamento.

As bibliotecas dos Tribunais de Contas do Brasil têm como objetivo prioritário apoiar os seus diversos setores no cumprimento de seus fins, constitucionalmente estabelecidos. Buscam, assim, suprir as necessidades 
de informações dos Conselheiros, Auditores, Técnicos e demais servidores das Casas, especialmente relacionadas ao controle externo da Administração Pública. Além desse público interno, atendem também às Prefeituras, Câmaras de Vereadores e às diversas entidades submetidas ao controle, fiscalização e orientação dos tribunais. Abrem-se, ainda, à sociedade em geral, disponibilizando a informação reunida em suas coleções (consulta no local) e bancos de dados (rede interna e internet). A pesquisa nos Tribunais de Contas do Brasil evidenciou que, do total de 34 Tribunais de Contas do Brasil, dentre os da União, Distrito Federal, Estados e Municípios, 29 contam com bibliotecas especializadas funcionando regularmente. Nestas, são em média 11 mil Membros e Servidores como usuários reais (cadastrados nas bibliotecas) e 15 mil como usuários potenciais.

O diagnóstico sobre a situação das bibliotecas dos Tribunais de Contas brasileiros revelou alguns dados que parecem indicar níveis diferenciados de desenvolvimento entre elas. Ao mesmo tempo em que temos bibliotecas com bons acervos, tratamento automatizado completo, acesso ao catálogo diversificado e oferecimento de produtos e serviços utilizando novas tecnologias, temos uma biblioteca que até sistema manual utiliza. Essas diferenças também foram observadas em relação à cooperação e intercâmbio. Tem-se bibliotecas que participam da Rede Bibliocontas, da Rede Virtual de Bibliotecas - Congresso Nacional e de Grupo Jurídico, mas temos também unidades de informação que não participam de nenhuma delas. Os serviços oferecidos pelas bibliotecas dos Tribunais de forma remota são ainda muito restritos. O mais amplamente encontrado é a disponibilização do catálogo via Web, que é um subproduto dos sistemas de automação das bibliotecas, já implementados na maioria das bibliotecas. São poucas as bibliotecas que estão se preparando para atuar de maneira compartilhada e integrada. É possível verificar aspectos positivos que viabilizam a efetiva integração entre as bibliotecas dos Tribunais em um trabalho em rede e a perspectiva de garantir que a produção institucional e intelectual de seus Membros e Servidores tenham uma maior visibilidade nas bases de dados locais e especializadas.

De posse dos dados do diagnóstico do ambiente de pesquisa, este foi submetido à apreciação dos especialistas em repositórios institucionais previamente selecionados.

Após o conhecimento da situação das bibliotecas, a técnica Delphi foi utilizada (dois rounds) e obteve-se o nível de consenso e permitiu trazer a experiência de quem está diretamente engajado no assunto para uma melhor compreensão de como propor a implantação do repositório nos Tribunais de Contas.

A seguir, são apresentados e analisados os principais resultados obtidos por meio da técnica Delphi.

A política de um repositório institucional, baseada na cultura das instituições, deve prever aspectos relativos a objetivos, diretrizes, práticas e intenções organizacionais e servirá para fortalecer as decisões a serem 
tomadas. Sobre a questão, o especialista 01 assim expôs seu ponto de vista:

Um repositório institucional - por definição - deve refletir com maior grau possível as especificidades da organização onde está inserida. Isso se aplica aos conteúdos que serão custodiados pelo repositório, às comunidades envolvidas na produção e no acesso aos conteúdos digitais e na gestão do repositório institucional. A própria forma como as informações estão organizadas devem espelhar a natureza do repositório. $A$ compreensão pela alta direção da organização da importância do repositório como um veículo de visibilidade, memória e testemunho das atividades que se desenrolam no âmbito da instituição é de fundamental importância para a sustentabilidade política e econômica desse serviço. Deve haver também um enquadramento ao ambiente tecnológico da instituição - principalmente em termos de tecnologia de informação e dos seus padrões, pois o repositório não pode ser um gueto tecnológico apartado das políticas praticadas na instituição.

Levar em conta o ambiente e os atores das instituições na definição do repositório institucional é considerado pela maioria dos especialistas 'extremamente relevante'. O especialista 02 fez a seguinte observação a respeito desta afirmativa:

O aspecto mais relevante de todo e qualquer repositório institucional é a aceitação pela alta administração da Instituição, seguido de um plano de convencimento e mudança de cultura da comunidade de autores e encerrando-se com um sistema fácil e estruturado de tal maneira a realmente corresponder às expectativas e cumprir com a promessa de aumento de visibilidade e acessibilidade.

O repositório deve ser um projeto em colaboração entre as diversas unidades das instituições, com representação de toda a instituição (TOMAÉL; SILVA, 2007).

É essencial a participação de um grupo com diferentes competências e influência na instituição para que as responsabilidades sejam divididas na definição da política para a implantação do repositório, em que se tomam decisões sobre padrões, softwares, os serviços a serem oferecidos, tipologia e conteúdo da coleção a ser incluída, preservação digital e sua funcionalidade.

Os custos de implementação do repositório estão relacionados, principalmente, ao grupo de trabalho (técnicos e especialistas) e aos equipamentos. $O$ especialista 01 salientou que: 
Subjacente ao repositório, há um conjunto de tecnologias, padrões, boas práticas, procedimentos administrativos, técnicas e metodologias que são domínios de várias áreas (administração, direito, tecnologia da informação, biblioteconomia, arquivologia e ciência da informação, design, arquitetura de informação, etc.), isto implica na necessidade da formação de equipes multidisciplinares e diálogos transversais que possam gerar uma matriz de conhecimento que deem sustentação a implantação e a evolução do repositório. Mas é necessário também um diálogo, em patamares práticos e teóricos com parceiros estratégicos, como, por exemplo, com o IBICT e com o CONARQ.

Os aspectos legais devem abranger questões relativas à licença de software, licença para publicar e propriedade intelectual, no que diz respeito à política de distribuição (TOMAÉL; SILVA, 2007). O software do repositório deve estabelecer limites para assegurar que esteja de acordo com a política, se houver limites na distribuição dos materiais ou nos níveis de acesso (DRAKE, 2004). Tais facetas, emblemáticas em ambientes físicos, tornam-se mais complexos no ambiente digital, local de difícil controle sobre as cópias. Segundo Tomaél e Silva (2007), as diretrizes relativas aos aspectos legais representam grande desafio para o gestor do repositório.

Os padrões a serem adotados no repositório são fundamentais para a definição do grau de interoperabilidade e de outros aspectos a serem implementados TOMAÉL; SILVA (2007). Quanto a esta afirmativa, o especialista 01 manifestou sua opinião da seguinte maneira:

O estabelecimento de uma política geral para o repositório deve contemplar com clareza os objetivos do sistema, incluindo as especificidades do seu público-alvo e a definição da tipologia e dos formatos dos materiais que serão custodiados pelo repositório, incluindo os fluxos que orientam a captura desses materiais e as regras de aceitação. Um dos itens importantes nesta política é, por exemplo, o delineamento das regras que regem a autossubmissão, que tem que levar em consideração o tratamento técnico, a intermediação, o versionamento etc.

O conteúdo de um repositório institucional está diretamente relacionado à comunidade de usuários que determina o que deve ser depositado e fica responsável de fazer o depósito. $O$ conteúdo do repositório institucional reflete o conhecimento, a pesquisa e o interesse de uma organização (TOMAÉL; SILVA, 2007).

$O$ especialista 03 acredita que:

Os repositórios podem armazenar desde informação científica, didática, burocrática, até as disseminadas pelos recursos de multimídia. 
Metadados são fundamentais na implementação de um repositório institucional, pois, além de descreverem os objetos, auxiliam na gestão dos arquivos de dados. Os autores estudados, são unânimes em afirmar que é necessário atentar para a questão dos metadados, que entraram no dia a dia dos seres humanos de uma forma natural, fruto da necessidade de se catalogar a informação. Gill et al. (2008), colocam que metadados são a soma total do que se pode dizer sobre um objeto de informação a qualquer nível de agregação. No que diz respeito aos metadados, o especialista 01 posicionou-se da seguinte maneira:

O conjunto de metadados definidos para o repositório deve ser capaz de assegurar uma representação para os objetos e coleções digitais que, além de permitir a recuperação e o acesso adequados aos interesses do público-alvo do repositório institucional, possa também ser um instrumento de gestão (por exemplo, de acesso e de copyright), de preservação e de curadoria dos materiais digitais. O perfil de aplicação dos metadados deve garantir também um nível semântico adequado para a interoperabilidade e intercâmbio de dados com outros sistemas afins.

O especialista 04 salientou que:

Os metadados têm o papel de descrever o objeto; a gestão de um arquivo é efetivamente realizada com um conjunto de políticas e instrumentos de preservação desse arquivo, e não somente com metadados.

A política de acesso e uso do repositório institucional, definição dos níveis de acesso e a indicação de um mediador/avaliador na submissão de trabalhos, segurança dos dados, sistema de ajuda (tutorial) são diretrizes que devem ser seguidas. Os itens destas alternativas devem fazer parte de um repositório institucional bem administrado.

Para assegurar a sustentabilidade do repositório institucional é necessário o apoio das altas administrações das instituições dos Tribunais e devem fazer parte do planejamento destas. Segundo Tomaél; Silva (2007), sem o comprometimento institucional com o projeto, os custos e as responsabilidades com um repositório institucional, serão, provavelmente, muito grandes, inviabilizando que um departamento ou unidade possam sustentá-los.

A preservação digital se refere a uma série de práticas que assegurem o acesso ao material digital, sempre que necessário. Na visão de Arellano (2008), a preservação lógica está relacionada à necessidade de garantir a conversão dos formatos que se tornaram ultrapassados ou com custos altos de manutenção, ou seja, o software e o hardware. Por seu lado, a preservação intelectual está relacionada ao seu conteúdo, a preservação da autenticidade, integridade e confiabilidade da informação no documento, haja vista que o documento em meio digital é passível de sofrer modificações. O especialista 01 assim observou: 
Quando uma organização assume a responsabilidade de implantar um repositório institucional, está implícito que ela tem o compromisso de prover o acesso por longo prazo aos conteúdos informacionais que serão lá depositados com os níveis de autenticidade e integridade exigidos pelas comunidades interessadas. Isto implica que os gestores do repositório institucional devem dispor de recursos metodológicos, tecnológicos e financeiros para garantir que os estoques informacionais digitais não sejam tragados pela obsolescência tecnológica e pela fragilidade intrínsecas das mídias digitais e que permaneçam viáveis, ou seja, legíveis e interpretáveis pelo tempo que for necessário.

As estatísticas podem auxiliar nos processos de avaliação do repositório institucional como forma de atrair o apoio institucional e aumentar a participação da comunidade com as publicações. $A$ participação da comunidade é o grande desafio.

Promover o repositório institucional junto à comunidade institucional é uma forma de motivá-la a utilizar os serviços. A promoção de ações de divulgação e marketing assegura a participação da comunidade. $O$ uso dessas ferramentas pode auxiliar na melhoria da visibilidade da produção técnica, artística, científica e cultural na organização.

Os principais papéis dos bibliotecários estão fundamentados na organização e manutenção de conteúdo digital, na produção de metadados e na atuação como agentes, com o intuito de assegurar o controle da qualidade dos registros produzidos, em atenção aos padrões internacionais (TOMAÉL; SILVA, 2007).

Os especialistas também consideram a implantação do repositório institucional uma inovação na gestão de documentos, mas também se referem à revisão da atual concepção das bibliotecas dos Tribunais de Contas, seus propósitos, objetivos e, finalmente, uso das tecnologias e adoção integral do processo de interatividade em sua potencialidade. Os avanços das tecnologias de constituição, interação e interoperabilidade têm e terão um considerável impacto no futuro dessas bibliotecas. 0 repositório precisa ser concebido de maneira integral, requerendo um alto nível de apoio e planejamento, assim como um bom nível de capacidades técnicas e de gestão, com recursos de TIC claramente alocados, com políticas de preservação digital eficazes e políticas institucionais que determinem e valorizem sua efetiva utilização. Quando uma instituição cria um recurso automatizado de tal porte, ela está reconhecendo que está tomando para si um compromisso de longo prazo.

0 especialista 05 sugeriu:

O estabelecimento de uma estrutura organizacional em rede para o funcionamento do repositório nos Tribunais de Contas.

Para o especialista 01 , o repositório institucional 
não deve ser uma memória estática. Ele deve ser uma plataforma para provimento de serviços informacionais voltados para os seus usuários e implementados por aplicações que atuam sobre os seus próprios estoques e pelos demais acervos afins que estão distribuídos e interoperáveis. Um exemplo para isso são os aplicativos para geração de conteúdos para curso à distância, ou para geração de indicadores em uma determinada área. $A$ integração às redes sociais e a personalização são fatores determinantes para o sucesso dos novos sistemas de informação.

A implantação dessas diretrizes suscitará a elaboração, discussão, regulamentação e estabelecimento de mecanismos específicos de forma a garantir a plena alimentação do repositório institucional e, por conseguinte, a preservação da produção institucional, intelectual e de gestão.

Assim, de posse do conjunto de indicadores apresentados e validados pelo painel de especialistas, foi possível propor elementos de diretrizes aplicáveis ao repositório institucional dos Tribunais: Institucionais, estruturais e operacionais.

Elementos institucionais:

Política de apoio - sem o comprometimento institucional não há repositório institucional;

Concepção estratégica - com base em diretrizes sistematizadas;

Recursos - humanos; tecnológicos; equipamentos.

Elementos estruturais:

- Objetivos/propósitos do repositório institucional - para quê;

- Implicados - unidades - biblioteca, informática e outros;

- Responsabilidades - alimentadores, revisores, desenvolvedores;

- Viabilidade técnica - computadores e artefatos tecnológicos.

Elementos operacionais

- Política de funcionamento - desenvolvimento de coleções; gestão da informação em ambiente digital e; direitos autorais;

- Gestão do repositório - observação de uma série de normativas e técnicas;

- Acesso ao conteúdo - usuários e grupos de usuários; 
- Processamento técnico da informação - [classificação; catalogação; indexação];

- Documentos a serem arquivados - digital; produzidos (autor ou co-autor) pelas instituições; autor deve conceder o direito não exclusivo de preservar e dar acesso ao seu trabalho por meio do repositório institucional.

- Criação de comunidades e de coleções - Tribunais e; documentos;

- Conteúdos que integrarão o repositório institucional itens.

O resultado do consenso nas afirmativas citadas acima representa o pensamento homogêneo dos especialistas quanto às diretrizes elencadas pela autora, com base na revisão de literatura, importantes para a implantação de repositório institucional nos Tribunais de Contas. A implantação do repositório é o reconhecimento de que a produção institucional da organização e a vida intelectual de seus Membros e Servidores serão progressivamente representadas, documentadas e compartilhadas de forma digital. Pois, antes de tudo, o conteúdo de um repositório destina-se ao compartilhamento.

\section{Considerações finais}

Assim como nas universidades e instituições de pesquisa, nas instituições públicas, grande parte da informação produzida não está disponível para a comunidade da própria instituição. Isso ocorre em função de vários aspectos que perpassam o ambiente da comunidade, dentre eles a grande quantidade de documentos publicados e nãopublicados ou não acessíveis que formam a massa de informação gerada que se perde porque não há formas eficientes de acesso a mesma.

O repositório institucional dos Tribunais de Contas do Brasil surge como uma opção de livre acesso à informação e propõe-se a estimular a disseminação dessa produção à comunidade. No geral, o repositório coopera para a visibilidade e impacto do conhecimento gerado nos Tribunais e compartilha este conhecimento interna e externamente à sua comunidade. Como decorrência, temas como direitos autorais, propriedade intelectual e formas de atuação cooperativas e integradoras devem ser iniciados e fortalecidos junto à comunidade envolvida.

A inovação arquitetural foi identificada na pesquisa. Os elementos estruturais são os seguintes: a) a implantação de repositório nos Tribunais é uma inovação arquitetural na concepção funcional das bibliotecas e b) a efetivação da inovação, no entanto, está sujeita à adoção das diretrizes de caráter: 1) institucional; 2) estrutural e 3) operacional.

Diretrizes de caráter Institucional asseguram a instauração do repositório institucional nos Tribunais; Diretrizes de caráter Estrutural 
formalizam e consolidam a estrutura dos elementos constituintes, suas ligações par-a-par e a hierarquia entre eles no repositório institucional; e Diretrizes de caráter Operacional determinam de que maneira os Repositórios Institucionais devem funcionar ou serem operacionalizados nos Tribunais. A inclusão dos repositórios nos Tribunais de Contas, de fato, introduz um elemento de inovação na função da biblioteca. Esse elemento (o repositório institucional) altera o elo entre os conceitos e os componentes essenciais, isto é, altera uma fonte material de informação e seu conteúdo (informação especializada, interpretada e recuperável que aumenta o conhecimento especializado da biblioteca), mas não altera o conceito central da biblioteca (ser um armazém de informações classificadas e recuperáveis).

São apresentadas finalmente recomendações no sentido de um possível aproveitamento das conclusões deste trabalho de investigação. Em primeiro lugar, uma estratégia de divulgação, promoção e formação é um fator abalizador para o êxito na implantação de um repositório, sendo que é indispensável para informar, clarear dúvidas e modificar aspectos que possam suscitar um baixo envolvimento por parte dos Membros e Servidores dos Tribunais. Em segundo lugar, o oferecimento de serviços de apoio - como o esclarecimento de questões como direitos do autor, depósito mediado e de valor agregado para as instituições e os autores como a geração de relatórios de estatísticas, citações e de relatórios de avaliações, dentre outros que compensem o esforço do auto-arquivo, é um ponto relevante. Em terceiro lugar, o que se afigura significativo, é a instituição de uma política que estimule ou obrigue o depósito da produção intelectual dos Membros e Servidores no RI, sendo esta custeada com ônus para os Tribunais.

O grupo foco, por meio da técnica Delphi permitiu aos especialistas apontarem elementos de diretrizes estruturantes (institucionais; estruturais; operacionais) para a construção de repositório institucional nos Tribunais de Contas do Brasil.

Serve ainda esta proposta de diretrizes para amparar estudos sobre o tema, e de base para a criação de repositórios em instituições com características semelhantes às aqui estudadas, guardadas as devidas proporções.

\section{Referências}

BRASIL. Constituição da República Federativa do Brasil de 1988.

Disponível em:

<http://www.planalto.gov.br/ccivil_03/constituicao/constitui\%C3\%A7ao.h tm. Acesso em: 20 jan. 2012.

COSTA, Sely M. S.; LEITE, Fernando César Lima. Insumos conceituais e práticas para iniciativas de repositórios institucionais de acesso aberto à informação científica em bibliotecas de pesquisa. In: SAYÃO, L. F. et al. Implantação e gestão de repositórios institucionais: políticas, memória, 
livre acesso e preservação. Salvador: EDUFBA, 2010. Disponível em: $<$ http://eprints.rclis.org/bitstream/10760/14906/1/Costa_\%26_Leite_2010.pdf >. Acesso em: 3 mar. 2012.

CROW, R. The case for institutional repositories: a SPARC position paper. Washington: Scholarly Publishing \& Academic Resources Coalition, 2002. Disponível em: <http://scholarship.utm.edu/20/1/SPARC 102.pdf>. Acesso em: 3 jun. 2013.

DAMANPOUR, Fariborz. Organizational innovation: a meta-analysis of effects of determinants and moderators. Academy of Management Journal, v. 34, n. 3, p. 555-590, 1991.

DRAKE, Miriam. Institutional repositories: hidden treasures. Searcher, v. 12, n. 5, maio, 2004. Disponível em:

< http://www.infotoday.com/SEARCHER/may04/drake.shtml> . Acesso em: 14 abr. 2012.

GILL, Tony et al. Introduction metadata. 2008. Disponível em:

< http://www.getty.edu/research/publications/electronic_publications/intrometadata/index. $>$. Acesso em: 20 ago. 2012.

GUERRA, Evandro Martins. Os controles externo e interno da Administração Pública e os Tribunais de Contas. Belo Horizonte: Fórum, 2003.

HELMER, O. The use of delphi technique in problems of educational innovations. Santa Mônica: Rand Corporation, 1966.

HENDERSON, R. M.; CLARK, K. Architectural innovation: the reconfiguration of existing product technologies and the failure of established firms. Administrative Science Quarterly, v. 35, n. 1, p. 9-30, mar. 1990.

IBICT. Acesso livre à informação científica impulsiona desenvolvimento do país. Disponível em: <http://www.ibict.br/noticia.php?id=596 >. Acesso em: 14 jan. 2012.

KNOX, Simon. The boardroom agenda: developing the innovative organization. Corporate Governance: International Journal of Business in Society, Bradford, v. 2, n. 1, p. 27-36, 2002.

KURAMOTO, H. Os open archive e as políticas públicas para a informação científica.

In: SIMPÓSIO INTERNACIONAL DE BIBLIOTECAS DIGITAIS, 3., 2005, São Paulo. Anais... Disponível em: 
<http://bibliotecascruesp.usp.br/bibliotecas/APRESENT/Helio_Kuramoto.p pt>. Acesso em: 16 maio 2012.

LANCASTER, F. W. Libraries and the future: essays on the library in the twenty-first century. New York: Hawork Press, 1993.

LEITE, Fernando C. L. Como gerenciar e ampliar a visibilidade da informação científica brasileira: repositórios institucionais de acesso aberto. Brasília: IBICT, 2009. Disponível em:

$<$ http://www.ibict.br/anexos_noticias/repositorios.institucionais.F.Leite_atualizado.pdf $>$. Acesso em: 12 jan. 2012.

LEITE, Fernando César Lima. Gestão da informação científica e repositórios institucionais de acesso aberto. In: SEMINÁRIO NACIONAL DE BIBLOTECAS UNIVERSITÁRIAS, 18., 2012. Anais... Gramado, 2012.

Disponível em:

<http://www.snbu2012.com.br/palestras/FERNANDO_CESAR_L._LEITE.pdf>. Acesso em: 22 nov. 2012.

LYNCH, C. A. Institutional repositories: essential infrastructure for scholarship in the digital age. ARL Bimonthly Report, 26, 2003. Disponível em:

<http://www.arl.org/newsltr/226/ir.html>. Acesso em: 7 maio 2012.

PROCÓPIO, Ednei. Construindo uma biblioteca digital. São Paulo: Edições inteligentes, 2005.

PROSSER, D. C. Open access: the future of scholarly communication. Cadernos $B A D$, n. 1, p. 6-20, 2005.

RIBEIRO JÚNIOR, Divino Ignácio. Implantação do repositório digital do projeto 'memória científica da Faed' com Dspace: relato de experiência. Revista ACB: Biblioteconomia em Santa Catarina, Florianópolis, v.17, n.1, p. 152-173, jan./jun., 2012.

SÁFADI, C. M. Q. Delphi: um estudo sobre sua aceitação. In: SEMINÁRIOS EM ADMINISTRAÇÃO, 5., São Paulo, 2001. Anais... São Paulo: FEA-USP, 2001. CD-Rom.

SAYÃO, Luis Fernando; MARCONDES, Carlos Henrique. Softwares livres para repositórios institucionais. In: Sayão, Luis Fernando et al. (Org.). Implantação e gestão de repositórios. Salvador: EDUFBA, 2009.

Disponível em:

<https://repositorio.ufba.br/ri/bitstream/ufba/473/3/implantacao_repositorio_web.pdf. $>$.

Acesso em: 22 out. 2012. 
SCHUMPETER, Joseph Alois. Capitalismo, socialismo e democracia. Rio de Janeiro: Fundo de Cultura,1961.

SILVA, Terezinha Elisabeth; ALCARÁ, Adriana Rosecler. Acesso aberto à informação científica: políticas e iniciativas governamentais. Informação \& Informação, Londrina, v. 14, n. 2, p. 100-116, jul./dez. 2009.

TOMAÉL, Maria Inês; SILVA, Terezinha. Elisabeth da. Repositórios institucionais: diretrizes para políticas de informação. In: ENCONTRO NACIONAL DE PESQUISA EM CIÊNCIA DA INFORMAÇÃO, 8., 2007, Salvador. Anais... Disponível em: <http://www.enancib.ppgci.ufba.br/artigos/GT5-142.pdf>. Acesso em: 22 mar. 2012. 